\title{
CONSUMO DE ALIMENTO POR UM GAFANHOTO NEOTRO- PICAL, Stenacris fissicauda fissicauda (BRUNER, 1908) (ORTHOPTERA:ACRIDIDAE) DA VÁRZEA AMAZÔNICA'
}

\author{
Maristela Ascenção AMORIM², Joachim ADIS ${ }^{3}$
}

\begin{abstract}
RESUMO - É feita a determinação da quantidade média (g) de biomassa foliar consumida por $1 \mathrm{~g}$ (peso seco) de gafanhoto/dia nesta espécic. O material para a realização dos experimentos foi coletado na llha de Marchantaria (várzea - Rio Solimões) perto de Manaus. Os animais testados foram agrupados por estádio ninfal (ninfas iniciais $(I+I I)$, médias $(I I I+I V)$ e finais $(V+V I)$ ) e os adultos pelo sexo (machos, lêmeas, machos+fêncas). A planta utilizada cono alimento foi Paspahum repens, macrófita aquática das Poaceac, onde Stenacris f. fissicauda desenvolve o seu ciclo vital. Verificou-se que as ninfas de estádios iniciais realizam o maior consumo $10.7740 \mathrm{~g} / \mathrm{g}$ de biomassa animal/dia), enquanto que o menor consumo de biomassa foliar, foi feito pelos adultos $(0,2622 \mathrm{~g} / \mathrm{g}$ de biomassa animal/dia). O consumo médio foi calculado em $0,5 \mathrm{~g}$ (peso seco) de biomassa foliar consumida por g (peso seco) de biomassa animal por dia. Estes dados estão sendo comparados com o consumo foliar de Cornops ayuaticum (Acrididae) em Eichhornia crassipes (Pontederiaceae) da mesma área.
\end{abstract}

Palavras-chave: Orthoptera, Acrididac, Consumo de Alimento, Macrótitas Aquáticas, Várzea.

Food consumption of a Neotropical grasshopper, Stenacris fissicanda fissicauda (Bruner, 1908) (Orthoptera:Acrididae) from the Amazonian "Varzea".

ABSTRACT - Average leal consumption of the grassbopper species Stenacris f, fissicauda is determined. The results are expressed as grams of leaf biomass/gram dry weight grasshopper/ day. The material used in the experiments was collected on Ilha de Marchantaria (island of "várzea" - Rio Solimões) near Manaus. The animals were grouped accoding to nymph stage (initial (I+II). middle (III+IV), final $(\mathrm{V}+\mathrm{VI})$ ), and sex (males, females, malestlemales). The plant used as food was Paspalum repens, an aquatic macrophyte of the Poaceac on which Stencacris f. fissicauda develops its life cycle. The initial stage nymphs consumed the most $(0.7740 \mathrm{~g} / \mathrm{g}$ of animal biomass/day), while the smallest consume of leaf hiomass was done by adults $(0.2622 \mathrm{~g} / \mathrm{g}$ of animal biomass/day). The calculated average consumption was about $0.5 \mathrm{~g}$ (dry weight) of leal biomass consumed per gram (dry weight) of animal biomass/day. Data are compared with leaf consumption of Comops aquaticum (Acrididac) on lählomma crassipess (Pontederiaceae) from the same area.

Key Words: Orthoptera, Acridiclac, Food Consumed, Aquatic Macrophytes, "Varzea".

\section{INTRODUÇÃO}

A vegetação da várzea é fortemente controlada pelo pulso de inundação (JUNK et al.,1989). As macrófitas aquáticas por possuírem adaptações à este fenômeno, além de uma grande velocidade de reprodução (JUNK, 1980; PIEDADE et (t..,1991), têm causado sérios problemas na utilização do ecossistema aquático.

Em represas tropicais, um dos

1 Parte da dissertação de mestrado, financiado pelo Projeto INPA/MAX-PLANCK alravés do Convênio INPA/MAX-PLANCK

2 M.Sc. Maristela Ascenção Amorim - Instituto Nacional de Pesquisas da Amarôntia (INPA). Caixa Postal 478 - 69.011-970 Manaus - Amazonas - Brasil.

3 Priv-Doz. Dr. Joachim Adis - Max-Planck-Instilut für Limunologic, AG Tropenkologie, Postfach 165. D - 24306 Plon, FRG. 
fenômenos mais alarmantes é o desenvolvimento, em massa, de macrófitas aquáticas. Isto se deve ao fato dessas plantas possuírem uma alta taxa de crescimento, além da existência de condições climáticas favoráveis e ao alto nível de nutrientes na água, devido à lixiviação do solo e à decomposição da vegetação submersa. Além desses fatores, pode-se citar ainda a falta de espécies competidoras bem como de animais herbívoros, pragas e doenças (JUNK \& MELLO, 1987).

O controle de macrófitas aquáticas através de herbicidas, muitas vezes não ¿ conveniente, principalmente se o reservatório for grande e existir na água uma grande disponibilidade de nutrientes, pois, devido ao crescimento rápido das plantas, essa operação deverá necessariamente ser contínua, requerendo muita mão-de-obra, acarretando com isso altos custos, sem considerar a intoxicação gradativa do ecossistema, incluindo o homem.

A prática do controle biológico em macrófitas aquáticas é relativamente nova. Estudos realizados em regiões tropicais, indicam diversos insetos como controladores dessas plantas. Os poucos experimentos realizados sobre o consumo destes insetos limitam-se aos danos observados na superfície foliar ou à relação entre a biomassa da planta consumida e o peso animal (CHISHOLM, 1979; UVAROV, 1977). Não se tem levado em consideração as flutuações na abundância e no desenvolvimento, nem da planta hospedeira nem do inseto controlador no habitat. Por isso, tornase difícil uma avaliação do impacto real do inseto sem o conhecimento da quantidade da planta hospedeira consumida por dia (peso seco) pela biomassa do agente controlador existente na área de estudo (peso seco por estádios de desenvolvimento) ao longo do ano. $\mathrm{O}$ trabalho aqui apresentado tenta fechar esta lacuna para Stenacris fissicauda fissicauda em Paspalum repens na várzea da Amazônia Central.

\section{MATERIAL E MÉTODOS}

Paspalum repens foi escolhida para servir de alimento ao gafanhoto durante os nossos experimentos pelo fato de Stenacris f. fissicauda desenvolver todo o seu ciclo vital na mesma (NUNES, 1989). Procuramos utilizar as plantas jovens na forma aquática, já que nesta espécie o teor de água muda ao longo do ano (Tab.1).

Os experimentos de consumo foram realizados em 18 e 30 de abril de 1989, porque no período da enchente observa-se a maior abundância de Stenacris $f$ fissicauda e de sua planta hospedeira (forma aquática) na Ilha de Marchantaria, conforme os dados elaborados por NUNES et al.(1992).

Para a realização deste experimento, foram coletados gafanhotos de todos os estádios ninfais e adultos, de ambos os sexos, em abril de 1989 (época chuvosa, período da enchente), na Ilha de Marchantaria. Utilizou-se o método de varredura com puçá para a captura dos mesmos. Após a coleta, os inimais eram colocidos em sacos plásticos cheios de ar e com folhas da macrófita hospedeira e, posteriormente, guardados em caixas térmicas de poliestireno (isopor) para o 
Tabela 1. Teor de água do caule de Paspalum repens (dados de JUNK, 1970, modificados).

\begin{tabular}{lcccc}
\hline & $\begin{array}{c}\text { FORMAAQUÁTICA } \\
\text { JOVEM }\end{array}$ & $\begin{array}{c}\text { PORMAAQUÁTCA } \\
\text { VEHA }\end{array}$ & FORMATERRESTRE \\
\hline $\begin{array}{l}\text { Comprimento total } \\
\text { do caule }\end{array}$ & $179 \mathrm{~cm}$ & $573 \mathrm{~cm}$ & $305 \mathrm{~cm}$ & $474 \mathrm{~cm}$ \\
Grossura do caule & \multicolumn{2}{c}{$0,7-1,0 \mathrm{~cm}$} & \multicolumn{2}{c}{$0,2-0,5 \mathrm{~cm}$} \\
Peso fresco & $54,3 \mathrm{~g}$ & $25,99 \mathrm{~g}$ & $29,0 \mathrm{~g}$ & $33,0 \mathrm{~g}$ \\
Peso seco & $2,5 \mathrm{~g}$ & $25,99 \mathrm{~g}$ & $6,6 \mathrm{~g}$ & $9,6 \mathrm{~g}$ \\
Teor de água & $95,4 \%$ & $85,2 \%$ & $77,2 \%$ & $70,9 \%$ \\
\hline
\end{tabular}

transporte até o laboratório.

Paspalum repens, macrófita da qual Stenacris fissicauda fissicanda se alimenta preferencialmente, foi trazida do campo em sacos plásticos (100 litros) com água, para o cultivo atrás do laboratório em tanques de cimento amianto com 1000 litros de capacidade, ao ar livre.

Os gafanhotos eram colocados no tanque com a macrófita, coberto por uma tampa de madeira e tela de nylon para evitar a fuga dos mesmos e o ataque dos predadores, principalmente de anuros. Os gafanhotos ficaram no tanque durante um determinado espaço de tempo (no mínimo 48 horas) para que houvesse aclimatização dos animais.

Foram preparados béqueres com algodão umedecido no fundo, onde foram colocadas folhas de Paspalum repens. Essas folhas foram cortadas no tanque e colocadas dentro de sacos plásticos para que não houvesse uma perda muito grande de água durante o intervalo de tempo entre o corte da folha e a pesagem, pois foi observado que a perda de água por essa planta ocorre muito rapidamente.

Com o auxílio de um aspirador entomológico, os gafanhotos eram retirados do tanque, separando-se as ninfas pelo estágio de desenvolvimento, e os adultos pelo sexo. Em seguida, foram pesados em balança analítica "Sartorius" ( \pm $0,0001 \mathrm{~g}$ ) dentro de um recipiente fechado (placa de Petri plástica).

Após as pesagens dos gafanhotos, esses foram colocados dentro dos béqueres e os mesmos foram fechados com filme de PVC.

As ninfas assim como os adultos, foram separados em grupos de 6 gafanhotos em cada béquer. Os béqueres apresentavam diferentes tamanhos, de acordo com o tamanho dos animais. Eles ficaram dispostos da seguinte forma:

BÉQUER 1 (300 ml) - 6 ninfas iniciais (estádio I + II).

BÉQUER $2(600 \mathrm{ml})-6$ ninfas finais (estádio V + VI).

BÉQUER $3(300 \mathrm{ml})-6$ ninfas médias (estádio III +IV). (우우).

BÉQUER $4(1000 \mathrm{ml})$ - 6 adultos

BÉQUER $5(1000 \mathrm{ml})-6$ aduitos ( $30^{x} 0^{x}$ e 3 웅).

BÉQUER $6(1000 \mathrm{ml})-6$ adultos $\left(0^{x} 0^{x}\right)$

Esses béqueres ficaram durante 72 
horas na parte dos fundos do laboratório, um galpão coberto com telhas de cimento amianto e aberto nas laterais. Após este tempo, os gafanhotos e o resto da planta foram pesados, os animais foram colocados em béqueres limpos com uma nova quantidade de alimento por mais 72 horas. $O$ resto da planta foi levado à estufa com $100^{\circ} \mathrm{C}$ por 24 horas.

Passadas as 72 horas, os gafanhotos e o que restou da planta foram novamente pesados, e em seguida os animais foram mortos através do frio (no freezer) e levados à estufa a $100^{\circ} \mathrm{C}$ juntamente com o resto da planta. Após 24 horas os gafanhotos e a planta foram retirados da estufa, colocados dentro de um dessecador e, depois de frios, pesados em balança unalítica, $\mathrm{O}$ uso do dessecador evita a "bsorção de umidade pelo material ainda quente. Desta forma se determinou o peso seco de ambos.

Os dados de consumo obtidos foram comparados a experimentos aleatórios de controle com animais capturados em julho de 1990 na Ilha de Marchantaria.

Determinação da relação entre peso fresco e o peso seco de Paspalum repens (Fator de conversão):

Para se determinar a quantidade de alimento (Paspalam repens) consumido por Stenacris fi fissicauda, foram feitos diversos cálculos, iniciando-se com o fator de conversão.

O fator de conversão é utilizado para transformar o peso fresco inicial de uma planta em peso seco inicial, já que não se pode determinar esse peso seco pelo método convencional (levar à estufa), pelo fato das folhas ainda não terem sido consumidas pelos gafanhotos.

Para se determinar o fator de conversão de Paspalum repens, pesou-se 50 folhas desta planta no período da manhã e no período da tarde em um único dia.

O fator de conversão foi obtido à partir de cálculos feitos com o peso fresco e seco das 50 folhas. Calcula-se quanto corresponde em peso seco, 1(um) grama de peso fresco de Paspalum repens.

$O$ valor encontrado para $P$. repens durante o período do experimento ( 181 $04 / 90$ e $08 / 05 / 90$ ), foi de $0,1703 \mathrm{~g}$, obtido através do seguinte cálculo:

PESO SECO DAS 50 FOLHAS DE Paspalum repens $($ manhã $)=5,761 \mathrm{~g}$

PESO SECO DAS 50 FOLHAS DE Paspalum repens (tarde) $=5,981 \mathrm{~g}$ $5,761 \mathrm{~g}+5,981 \mathrm{~g}=11,742 \mathrm{~g} \div 2=5,871 \mathrm{~g}$ $1 \div 5,87 \mathrm{Ig}=0,1703 \mathrm{~g}$

FATOR DE CONVERSÃO $=0,1703$.

Esse fator de conversão foi multiplicado pelo peso fresco inicial das plantas usadas no experimento de consumo. O resultado obtido correspondeu ao peso seco das folhas do início do experimento (antes de serem consumidas).

A razão pela qual todos os cálculos foram feitos utilizando-se somente o peso seco, foi para se diminuir o erro que pode ocorrer quando se usa o peso fresco, pois a quantidade de água pode variar, como por exemplo, a folha da planta pode aumentar de peso com água que ela absorve do algodão umedecido, onde fica durante o experimento, conforme foi comprovado em experimentos preliminares. 
O fator de conversão de Paspalum repens deve ser calculado toda vez que se realizar um experimento desta natureza com esta espécie de macrófita, pois $\varphi$ fator mudará ao longo do ano. $\mathrm{O}$ que promove esta mudança é o fato desta planta ter diferentes quantidades de água, nas diferentes formas de crescimento e durante as fases de enchente e vazante, como já vimos anteriormente na Tab.1.

Cálculo para determinação da quantidade de Paspalum repens consumido por Stenacris fissicauda fissicauda.

Para calcularmos o consumo médio de Paspalum repens por Stenacris fissicauda fissicauda, foi necessário conhecermos o tempo médio de desenvolvimento pós embrionário, o peso seco médio $(\mathrm{g})$ de cada estádio ninfal, a abundância média (indivíduos $/ \mathrm{m}^{2}$ ), a biomassa média do animal (peso $\mathrm{sec} / \mathrm{m}^{2}$ ), a biomassa média da planta (peso seco/ $\mathrm{m}^{2}$ ) e a variação do nível da água.

No experimento 1 (Tab. 2), as seis ninfas foram pesadas obtendo-se um peso fresco médio inicial de $1,0587 \mathrm{~g}$. Após 3 dias, o peso fresco médio (final) foi 1,1423 g. Depois de renovado o alimento, (experimento 2 ; Tab. 2), e no final de 72 horas, o peso fresco médio dos gafanhotos foi $1,2503 \mathrm{~g}$. Depois de mortos pelo frio e levados à estufa, obteve-se um peso seco médio de $0,3269 \mathrm{~g}$.

Devido ao fato de termos calculado tudo em peso seco, tornou-se necessário converter o peso fresco inicial em peso seco inicial.

O cálculo foi realizado usando-se a seguinte fórmula :

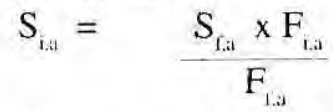
animais

$\mathrm{F}_{\text {i.a. }}=$ peso fresco inicial dos animais.

$\mathrm{S}_{\mathrm{i.a}}=$ peso seco inicial dos

$\mathrm{F}_{\mathrm{i}: \mathrm{i}}=$ peso fresco final dos animais

$\mathrm{S}_{\mathrm{b}}=$ peso seco final dos animais.

Experimento 1: $S_{1.1}=0,3269 \times 1,0587=$ 1,1423

$0,3030 \mathrm{~g} / 6$ animais

Peso médio dos animais; $S_{t: a}+S_{t . i .}$ $=0,3030 \mathrm{~g}+0,3269 \mathrm{~g}$

Tabela 2. Experimento de consumo de alimento (Paspalum repens), realizado com seis ninfas finais $\left(5^{\circ}\right.$ e $6^{\circ}$ estádio) de Stenacris fissicauda fissicauda (2-7.05.1990).

\begin{tabular}{|c|c|c|c|}
\hline \multicolumn{4}{|c|}{ EXPERIMENTO 1} \\
\hline $\begin{array}{l}\text { Conteúdo do } \\
\text { béquer }\end{array}$ & $\begin{array}{c}\text { Peso Fresco } \\
\text { inicial }(\mathrm{g})\end{array}$ & $\begin{array}{l}\text { Peso Fresco } \\
\text { final }(\mathrm{g})\end{array}$ & $\begin{array}{c}\text { Peso Seco final } \\
\text { (g) }\end{array}$ \\
\hline$P$. repens & 3.5616 & 0.8961 & 0.1469 \\
\hline S. f. fissicauda & 1.0587 & 1.1423 & -- \\
\hline \multicolumn{4}{|c|}{ EXPERIMENTO 2} \\
\hline $\begin{array}{l}\text { Conteùdo do } \\
\text { béquer }\end{array}$ & $\begin{array}{l}\text { Peso fresco } \\
\text { inicial }(g)\end{array}$ & $\begin{array}{c}\text { Peso Fresco } \\
\text { final }(\mathrm{g})\end{array}$ & $\begin{array}{c}\text { Peso Seco final } \\
\text { (g) }\end{array}$ \\
\hline P. repens & 4.441 & 2.8214 & 0.3683 \\
\hline S. f. fissicauda & 1.1423 & 1.2503 & 0.3269 \\
\hline
\end{tabular}


$=0,6299: 2$

$=0,3150 \mathrm{~g} / 6$ animais

Peso médio por animal: $0,3150 \mathrm{~g} \div 6$ $=0,0525 \mathrm{~g} /$ animal .

Comparando este valor obtido em nosso experimento, $0,0525 \mathrm{~g} /$ animal (ninfas de estádio final), com o encontrado por NUNES (1989) (Tab. 3), qùe determinou o peso seco de todos os estádios ninfais de Stenacris fissicauda fissicauda (Tab. 3), verifica-se que este encontra-se entre a faixa de valores obtidos pelo autor para a ninfa $\mathrm{V}(0,04190 \mathrm{~g}) \mathrm{e}$ ninfa VI $(0,07620)$.

Só foram utilizados para os cálculos a seguir os dados do experimento 1, pois no experimento 2 uma ninfa sofreu ecdise, ' os dados foram descartados, já que não - xpressaram o consumo "real" daquele stágio.

No processo de muda foi observado que as ninfas até o $3^{\circ}$ estádio, param de se alimentar algumas horas antes da ecdise, enquanto que as de estádios posteriores ( $4^{\circ}$, $5^{\circ}$ e $6^{\circ}$ estádios), param de se alimentar e defecar cerca de 1-2 dias antes, (NUNES,1989).

A planta utilizada como alimento também teve o seu peso fresco convertido em peso seco, através do seguinte cálculo:

\section{$S_{i, p}=F_{i, j} \times$ Fator de conversão}

$\mathrm{S}_{\mathrm{i}, \mathrm{p}}=$ peso seco inicial da planta

$F_{i, p}=$ peso fresco inicial da planta

Valor encontrado no Experimento $1 \mathrm{~S}_{\mathrm{it} / \mathrm{f}}$ $=3,5616 \times 0,1703=0,6065 \mathrm{~g}$

Para determinarmos a quantidade de alimento consumido, tiramos a diferença entre $S_{i, j,}$ e o $S_{i, f}$,
$\mathrm{S}_{\mathrm{i}, \mathrm{p}}-\mathrm{S}_{\mathrm{l}, \mathrm{p}}=$ Alimento consumido

$0,6065-0,1469=0,4596 \mathrm{~g} / 6$ animais/

3 dias, ou seja, 0,0255 g/animal/dia.

Sendo que o peso seco médio de um animal é $0,0525 \mathrm{~g}$, o consumo médio de planta seca por dia por $1 \mathrm{~g}$ de peso seco de animal é :

$0,0255=0,505 \mathrm{~g}$ de planta $/ \mathrm{g}$ animal $/$ dia $0,0525=0,5050 \mathrm{~g} \mathrm{x} \mathrm{g}^{-1} \mathrm{x} \mathrm{d}^{-1}$.

Depois de calcular o consumo médio por estádio, fez-se o cálculo do consumo acumulativo, que é o resultado da multiplicação de três fatores :

1. Peso seco médio do gafanhoto por estádio;

2. Duração média dos estádios ninfais;

3. Consumo médio de alimento por estádio.

Para exemplificar o cálculo do consumo acumulativo, as ninfas dos estádios I e II (ninfas iniciais), tiveram, respectivamente, peso seco médio igual a 0,00245 g e $0,00668 \mathrm{~g}$ (Tab. 3), duração dos estádios 8,4 e 8,2 dias e consumo de alimento de $0,415 \mathrm{e} 1,131 \mathrm{~g} \mathrm{x} \mathrm{g}^{-1} \mathrm{x} \mathrm{d}^{-1}$. O consumo acumulativo dos dois estádios foi

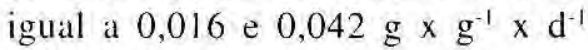
respectivamente.

\section{RESULTADOS}

No experimento de consumo foi constatado que as ninfas iniciais, que conrespondem às ninfas dos estádios I I II, consumiram na média $0,7740 \mathrm{~g}$ de planta (peso seco) por grama de gafanhoto (peso seco) por dia (Fig. I; Tab. 5),

Os jovens do estádio I levaram em média 8,4 dias para chegarem ao fím deste 
estádio, enquanto as ninfas do estádio II, gastaram na média 8,2 dias para isto. Podese dizer então, que as ninfas dos estádios iniciais (I e II), tiveram um tempo médio de 16,6 dias nessas duas etapas do seu desenvolvimento (Tab. 4).

Os imaturos dos estádios III e IV (ninfas médias), consumiram na média 0,4727 g/g animal/dia (Fig.1); passando a ninfa III um tempo médio de 8,4 dias neste estádio. As ninfas IV chegaram ao final desta fase do desenvolvimento na média em 10,3 dias. A média de tempo gasto nessas duas fases do desenvolvimento foi de 35,3 dias (Tab. 4).

As ninfas dos estádios finais ( $V$ e VI), foram responsáveis pelo

Tabela 3. Peso seco médio (g) de imaturos e adultos de Stenacris fissicauda fissicauda. *

\section{ESTÁDIO DE DESENVOLVIMENTO}

PESO SECO ( $(\mathrm{g})$

$\begin{array}{ccc}\text { Ninfa } & \text { I } & 0.00245 \\ \text { Ninfa } & \text { II } & 0.00668 \\ \text { Ninfa } & \text { II } & 0.01706 \\ \text { Ninfa } & \text { IV } & 0.03346 \\ \text { Ninfa } & \text { V } & 0.04190 \\ \text { Ninfa } & \text { VI } & 0.07620 \\ \text { Fêmeas } & - & 0.13450 \\ \text { Machos } & - & 0.07040\end{array}$

* Dados elaborados de dados brutos apresentados nas Tabelas 1 e 4 do apéndice em NUNES, 1989.

consumo médio de $0,5023 \mathrm{~g} / \mathrm{g}$ animal/ dia (Fig.1; Tab. 5). O estádio V, durou em média de 14,7 dias. Ao final deste estádio, os machos atingiram o estágio adulto (Tab. 4).

O estádio VI foi apresentado somente pelas fêmeas, e o tempo de duração média deste estádio ficou em 18,5 dias (Tab. 4).

Os gafanhotos adultos mantidos em cativeiro por 14 dias, foram responsáveis por uma parcela de consumo médio de $0,2622 \mathrm{~g}$ de Paspalum repens por grama de gafanhoto por dia (Fig.1; Tab. 5).

O consumo médio de Paspalum repens por ninfas e adultos de Stenacris fissicauda fissicauda, foi de $0,5028 \mathrm{~g}$ de biomassa foliar/g de biomassa animal/ dia (pesos secos) (Fig.1).

O consumo acumulativo (Tab. 5) correspondeu a quantidade de alimento (biomassa foliar de $P$. repens) que Stenacris f. fissicauda consumiu durante um período de aproximadamente 80 dias (ninfa I até adulto).

No consumo acumulativo (grama de biomassa foliar/grama de biomassa animal por estádios) (Fig. 2), as ninfas iniciais (I+II) realizaram um consumo médio de $0,58 \times 10^{-1} \mathrm{~g}$ em 16,6 dias, somando-se com as ninfas médias (III+IV), o consumo médio foi igual a $2,89 \times 10^{-1} \mathrm{~g} \mathrm{em} \mathrm{35,3} \mathrm{dias,}$ juntando-se com as ninfas finais $(\mathrm{V}+\mathrm{VI})$, o consumo médio totalizou $5,98 \times 10^{-1} \mathrm{~g}$ em 68,5 dias. $O$ consumo médio dos machos com biomassa média igual a 7,04 $\mathrm{x}$ $10^{-1} \mathrm{~g}$ foi na média $7,33 \times 10^{-1} \mathrm{~g}$ de biomassa foliar; nas fêmeas, que tiveram uma biomassa média igual a $13,45 \times 10^{-1}$ $\mathrm{g}$, a biomassa média foliar consumida foi de $15,35 \times 10^{-1} \mathrm{~g}$, com um tempo de 14 dias de vida, mantidos em cativeiro. Assim o consumo acumulativo de Stenacris $f$. fissicaucla durante o seu desenvolvimento, considerando-se o consumo médio de adultos (machos e fêmeas), foi de $11,34 \mathrm{x}$ $10^{-1} \mathrm{~g}$ de biomassa foliar para um peso 


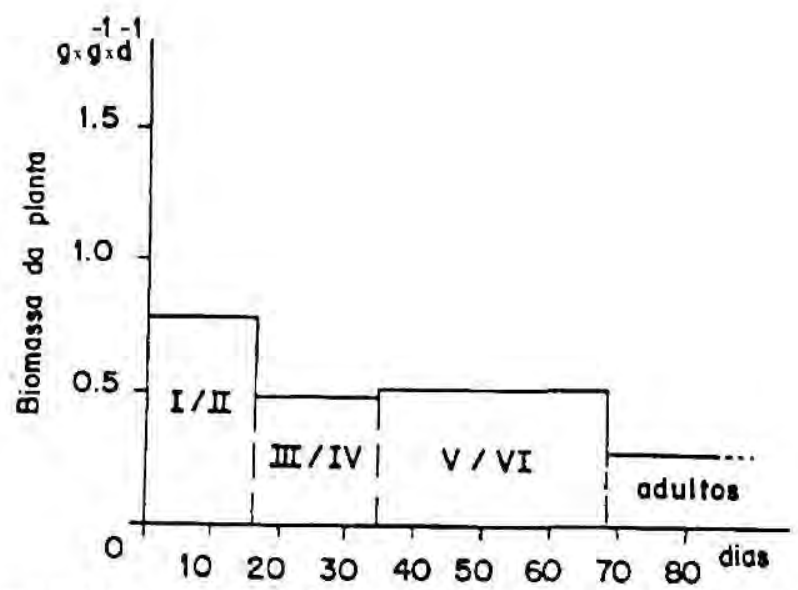

Figura 1. Consumo médio (em dias) da biomassa foliar (peso seco) de Paspalum repens por grama de massa animal (peso seco) para ninfas iniciais (I/II), médias (III/IV), finais (V/VI) e adultos $\left(0^{x} 0^{x}+7 q\right)$.

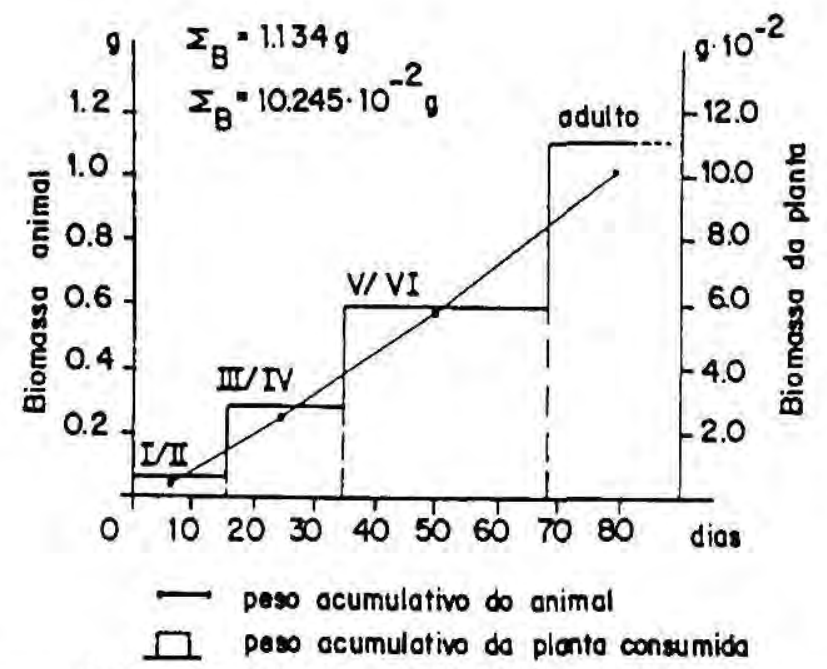

Figura 2. Biomassa foliar acumulativa consumida (média em dias) em comparação com o incremento do peso animal durante o desenvolvimento. Para os adultos se projetou uma média de 14 dias (manutenção em cativeiro). Biomassa foliar (peso seco) consumida por $0^{x}=7,33 \times 10$

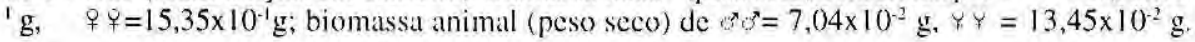
$\Sigma_{\mathrm{B}}=$ biomassa animal total acumulada;

$\Sigma_{\mathrm{w}}=$ biomassa foliar total consumida. 
Tabela 4. Duração média do desenvolvimento pós-embrionário de Stenacris fissićcauda fissicauda. *

\begin{tabular}{cccc}
\hline \multirow{2}{*}{$\begin{array}{c}\text { ESTÁDIO DE } \\
\text { DESENVOLVIMENTO }\end{array}$} & \multicolumn{3}{c}{ DURAÇÃO MÉdIA (dias) } \\
\cline { 2 - 4 } & 97 & $80^{*}$ & $+7+$ + \\
\hline I & 7,6 & 9,1 & 8,4 \\
II & 8,5 & 7,9 & 8,4 \\
III & 8,3 & 8,4 & 8,4 \\
N & 9,8 & 10,8 & 10,3 \\
V & 13,3 & 16,1 & 14,7 \\
VI & 18,5 & $* \star$ & 18,5 \\
Total & 66,0 & 52,3 & 59,2 \\
\hline
\end{tabular}

* Dados modificados de NUNES (1989).

** Ausência deste estádio nos machos.

Tabela 5. Consumo acumulativo (g peso seco) de Paspahum repens em experimentos com ninfas iniciais, médias, finais e adultos de ambos os sexos de Stenacris fissicatada fissicauda.

\begin{tabular}{|c|c|c|c|c|}
\hline ESTÁDKO & $\begin{array}{c}\text { PESO SECO } \\
(\mathrm{g})^{\star}\end{array}$ & $\begin{array}{c}\text { CONSUMO } \\
(g \times g-1 \times d-1)^{\star \star}\end{array}$ & $\begin{array}{c}\text { DURAÇÃO } \\
\text { (dias) }\end{array}$ & $\begin{array}{l}\text { CONSUMO ACUMULATINO } \\
\text { (p.s. } x \text { con. } x \text { duração) }^{\star \star \star \star}\end{array}$ \\
\hline $\begin{array}{c}1+\| \\
\text { (iniciais) }\end{array}$ & 0,00457 & 0,774 & 16,6 & 0,058 \\
\hline $\begin{array}{c}\text { III + IV } \\
\text { (médias) }\end{array}$ & 0,02526 & 0,4727 & 35,3 & 0,231 \\
\hline $\begin{array}{c}\mathrm{V}+\mathrm{VI} \\
\text { (finais) }\end{array}$ & 0,05905 & 0,5023 & 68,5 & 0,017 \\
\hline $\begin{array}{c}7+{ }^{*} \\
\text { (Adultos) }\end{array}$ & 0,10245 & 0,2622 & 75,5 & 0,134 \\
\hline
\end{tabular}

* $(\mathrm{g})=$ peso seco médio em grama.

** $($ gxg-1 $\times d-1)=$ peso seco médio da planta consumida $/ \mathrm{g}$ de peso seco de gafanhoto/dia.

*** $($ p. s. $x$ con. $x$ duração $)=$ peso seco médio de gafanhoto $x$ média de alimento consumido $x$ duração média do estádio de desenvolvimento em dias. 
Tabela 6. Consumo acumulativo (g peso seco) de Paspalum repens calculado por ninfas e adultos de ambos os sexos de Stenacris fissicauda fissicauda.

\begin{tabular}{ccccc}
\hline ESTÁDIO & $\begin{array}{c}\text { PESO SECO } \\
(\mathbf{g})^{*}\end{array}$ & $\begin{array}{c}\text { CONSUMO } \\
(\mathbf{g} \times \mathbf{g}-\mathbf{1} \times \mathbf{~ d ~}-1)^{* *}\end{array}$ & $\begin{array}{c}\text { DURAÇÃO } \\
(\text { dias })\end{array}$ & $\begin{array}{c}\text { CONSUMO ACUMULATNO } \\
(\text { p.s. } \times \text { con. } \times \text { duração) })^{* * *}\end{array}$ \\
\hline I & 0,00245 & 0,4150 & 8,4 & 0,016 \\
II & 0,00668 & 1,3110 & 8,2 & 0,042 \\
III & 0,01706 & 0,3193 & 8,4 & 0,068 \\
N & 0,03346 & 0,6261 & 10,3 & 0,163 \\
V & 0,04190 & 0,3564 & 14,7 & 0,309 \\
VI & 0,07620 & 0,6482 & 18,5 & 0,708 \\
$q$ & 0,13450 & 0,229 & 7,0 & 1,535 \\
O & 0,07040 & 0,135 & 7,0 & 0,733 \\
\hline
\end{tabular}

$*(\mathrm{~g})=$ peso seco médio em grama.

** $(\mathrm{gxg}-1 \times \mathrm{xd}-1)=$ peso seco médio da planta consumida $/ \mathrm{g}$ de peso seco de gafanhoto/dia.

${ }^{\star \star \star}$ ( p. s. $x$ con. $x$ duração $)=$ peso seco médio de gafanhoto $x$ média de alimento consumido $x$ duração média do estádio de desenvolvimento em dias.

acumulado de $10,245 \times 10^{-2} \mathrm{~g}$ de biomassa animal (pesos secos).

\section{DISCUSSÃO}

O consumo de folhas de Paspalum repens por Stenacris fissicauda fissicauda, foi analizado tomando-se em conta a idade (estádio de desenvolvimento) e o sexo do inseto.

A comparação entre os estádios ninfais (fêmeas com 6 e machos com 5 estádios ninfais ) e adultos (sexos juntos e separados), mostrou que as ninfas iniciais $(I+I I)$ foram as que mais consumiram alimento, mesmo comparando-se com o consumo dos adultos, onde temos que levar em consideração a diferença do peso e do tamanho do corpo. Para as ninfas médias (III + IV), ocorreu uma redução no consumo de alimento, para em seguida aumentar com as ninfas linais (V+VI) (Fig. 1).
Os grupos de ninfas, de maneira geral, mostraram um consumo maior que os adultos. Isto pode ser explicado pela necessidade de uma quantidade maior de alimento em função do crescimento corporal, a formação das asas, etc. Mesmo ocorrendo o processo de ecdise durante o desenvolvimento ninfal, quando ocorre uma parada na alimentação (NUNES, 1989), o consumo continuou sendo maior nesta fase da vida desta espécie de gafanhoto.

Nos gafanhotos adultos, as fêmeas sempre mostraram um consumo maior, o que se deve ao seu maior tamanho e peso corporal que também é maior que nos machos. Outra explicação é que a produção de ovos requer uma quantidade maior de alimento do que a produção de esperma (LANGFORD, 1930).

Outros estudos feitos sobre o consumo de alimento por gafanhotos, mostraram também este resultado. 
WHITE \& WATSON (1972), estudando o consumo de Gentiana corymbifera (Gentianaceae)por tres espécies da família Acrididae, Paprides nitidus, Sigaus australis e Brachaspis nivalis, fazem uma relação entre alimento consumido por peso do animal por estádio e sexo por dia, constatando que as fêmeas das três espécies estudadas realizaram um consumo maior em todas as idades.

ANANTHAKRISHNAN et al. (1986), estudando a relação entre o índice de desenvolvimento pósembrionário/índice de crescimento/ quantidade de alimento utilizado pelo gafanhoto Cyrtacanthacris ranacea em algodão (Malvaceae), Gossypium hirsutum, Abelmoschus esculentus, Abutilon indicum e Sida rhomboidea, concluiu que o primeiro estádio consome mais alimento sem distinção de planta e, entre os adultos, o consumo maior é sempre das fêmeas em todas as plantas testadas.

ADIS \& JUNK (em preparação; apud JUNK,1990), realizaram um experimento de consumo foliar em Eichhornia crassipes (Pontederiacae) por Cornops aquaticum (Acrididae) da mesma área de estudo, e verificaram que durante o desenvolvimento ninfal desta espécie, as ninfas do primeiro estádio têm um consumo maior, sendo seguidas pelas ninfas de segundo estádio. Isto reforça os dados obtidos para Stenacris fissicauda fissicauda.

Quanto aos adultos, as fềmeas de Cornops aquaticum alcançaram uma biomassa média de $0,093 \mathrm{~g}$ (peso seco) e consumiram na média $1,760 \mathrm{~g}$ de biomassa foliar/dia (peso seco), enquanto que as fêmeas de Stenacris $f$. fissicauda, atingiram a biomassa média de $0,135 \mathrm{~g}$ (peso seco) e um consumo médio de $1,535 \mathrm{~g}$ de biomassa foliar/dia (peso seco). Os machos de Cornops aquaticum atingiram uma biomassa média de $0,058 \mathrm{~g}$ (peso seco) e o consumo médio de 1,59 g de biomassa foliar/dia (peso seco); já os machos de Stenacris f. fissicauda perfizeram 0,0704 $\mathrm{g}$ (peso seco) de biomassa média e consumiram na média $0,733 \mathrm{~g}$ de biomassa foliar/dia (peso seco) (Fig. 3). Os dados representam o período de inundação no campo.

O consumo médio dessas duas espécies, ficou em $0,9 \mathrm{~g}$ de biomassa foliar (peso seco) consumida por $g$ de biomassa animal (peso seco) em um dia para Cornops aquaticum, e de 0,5 g para Stenacris f. fissicauda.

O consumo médio diário da população de Stenacris $f$. fissicauda resulta da multiplicação da biomassa média de gafanhotos existentes no campo com a taxa diária de consumo médio $(0,9 \mathrm{~g}$ de biomassa foliar por $1 \mathrm{~g}$ de biomassa animal, ambas em peso seco). O consumo médio diário variou entre $0,01 \mathrm{~g} \mathrm{x} \mathrm{m}^{-2} \mathrm{x} \mathrm{d}^{-1} \mathrm{em}$ julho (água descendo) e $0,41 \mathrm{~g} \mathrm{x} \mathrm{m}^{-2} \mathrm{x} \mathrm{d}^{-1}$ em janeiro (água subindo; Fig. 3).

O cálculo de uma média para o ano todo não é possível devido a grande variação tanto na abundância dos gafanhotos como na planta hospedeira. Porém, em comparação com o consumo médio diário de Cornops aquaticum, o qual variou entre 0,1 e $2,3 \mathrm{gxm}^{-2} \mathrm{x} \mathrm{d}^{-1}$ durante o ano (ADIS \& JUNK em preparação; apud JUNK, 1990), o 
consumo de Stenacris $f$. fissicauda é bem menor. O desenvolvimento embrionário mais longo em Cornops aquaticum (incubação de ovos $=27 \pm 3$ dias, Stenacris $f$. fissicauda $=19,5 \pm 3,5$ dias) é compensado por um desenvolvimento pós-embrionário mais rápido (para 5 e 6 estádios ninfais: aproximadamente 48 dias em Cornops aquaticum e 59 dias em Stenacris $f$. fissicauda) e uma abundância maior na planta hospedeira (média anual por mês $=7,2$ ind $\mathrm{x} \mathrm{m}^{-2}$ para C. aquaticum $\mathrm{e} 3,2$ ind $\mathrm{x} \mathrm{m}^{-2}$ para S.f. fissicauda; ADIS, comunicação pessoal; NUNES et al., 1992). De fato, o dano foliar observado no campo em Eichhornia crassipes é mais óbvio do que em Paspalum repens.

\section{AGRADECIMENTOS}

Agradecemos aos colegas do Projeto INPA/MAX-PLANCK e do Instituto Nacional de Pesquisas da Amazônia (INPA) em Manaus (Brasil), assim como do Grupo de Ecologia Tropical do Instituto MaxPlanck para Limnologia em Plön (Alemanha), pela valiosa ajuda recebida. Agradecimentos especiais ao técnico Edilson de Araujo Silva, assim como ao Sr. José Fernandes Soares e família do laboratório flutuante "Harald Sioli" na Ilha de Marchantaria, por todo apoio prestada. Agradecemos à Dra. Ilse Walker e à M.Sc. Elizabeth Franklin pelos

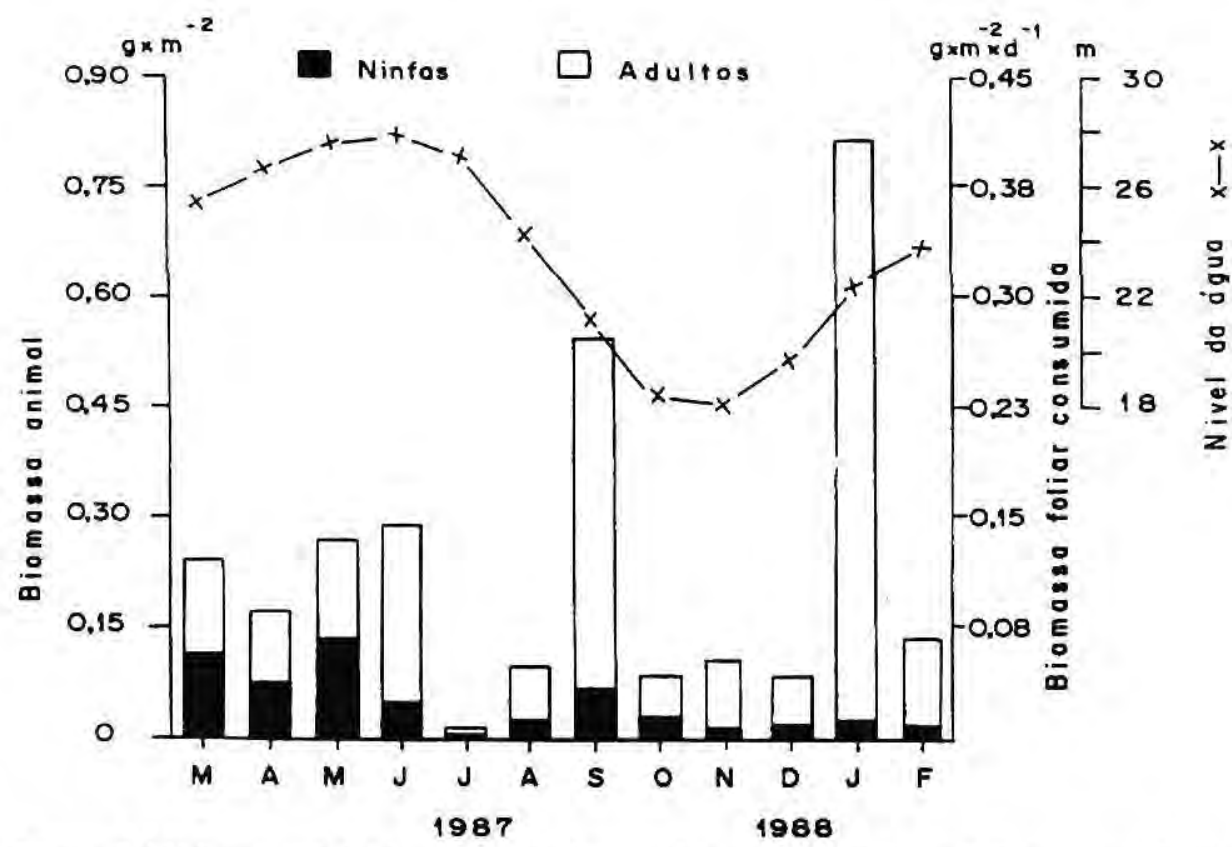

Figura 3. Média mensal da biomassa animal $\left(\mathrm{g} \mathrm{x} \mathrm{m}^{-2}\right)$ e média dabiomassa foliar consumida por

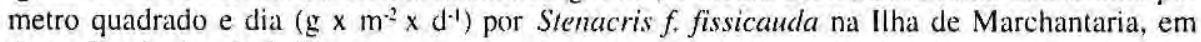
dependência do nível d'água. 
comentários recebidos no manuscrito.

\section{Bibliografia citada}

ANANTHAKRISHNAN,T.N.; SANJAYAN,K.P. \& SURESH KUMAR,N. 1986. Host plant preferences in Cyrtacanthacris ranacea Stoll in some Malvaceous hosts in terms of food utilization. Proc. Indian. natn. Sci. Acad., 51(3): 351-357.

CHISHOLM,I.F. 1979. A laboratory investigation d Paulinia acuminata (De Geer) (Orthoptera:Acrididae) as a biological control agent for Salvinia molesta. Bull. ent. Res., $69: 111-114$.

JUNK,W.J, 1970. Investigations on the ecology and production-biology of the "floating meadows" Paspalo-Echinochloetum on the Middle Amazon. I. The floating vegetation and its ecology, Amazoniana, 2(4): 449-495.

JUNK,W.J. 1980. Areas inundáveis - Um desafio para Limnologia. Acta Amazonica, 10(4):775-795.

JUNK,W.J. 1990. Die Krautvegetation der Várzea. Tese de Livre Docência, Universidade de Hamburgo, Alemanha. 349 p.

JUNK,W.J. \& MELLO,J.A.S.N. de 1987. Impactos ecológicos das represas hidrelétricas na Bacia Amazônica Brasileira.Tübinger Geographische Studien, 95:367-385.

JUNK,W.J.; BAYLEY,P.B. \& SPARKS,R.E. 1989. The flood pulse concept in river-floodplain systems. Can. Spec. Publ. Fis/. Aquat. Sci., 106:110-127.
LANGFORD, G.S. 1930. Some factors relating to the feeding habit of grasshoppers. Colorado Agricultural College, Bulletin 354, 53p.

NUNES,A.L. 1989. Estudos sobre o ciclo de vida e fenologia de Stenacris fissicauda fissicauda, (Bnuner,1908) (ORTHOPTERA - ACRIDIDAE) em um lago de várzea da Amazônia Central, Brasil. Tese de Mestrado, CPG INPA/FUA, 122p.

NUNES,A.L.; ADIS,J. \& MELLO,J.A.S.N. de 1992. Estudos sobre o ciclo de vida e fenologia de Stenacris fissicauda fissicauda (Bruner, 1908) (Orthoptera-Acrididae) em um lago de várzea da Amazônia Central, Brasil. Boletin do Museu Paraense Emilio Goeldi, Série Zoologia, 8(2):349-474.

PIEDADE,M.T.F.; JUNK,W.J. \& NUNES DE MELLO,J.A. 1991: A floodplain grassland of the central Amazon.- In: LONG, S. P. ; J ONES, M . B . \& ROBERTS,M.J.(eds.).Primary productivy of grass ecosystems of the tropics and sub-tropics. UNEP, London (Chapman \& Hall), $127-$ 158.

UVAROV,B. 1977. Grasshoppers and locusts - A handbook of general acridology - behaviour, ecology, biogeography and population dynamics. Centre for Overseas Pest Research, 2:114-122.

WHITE,E.G. \& WATSON,R.N. 1972. A food consumption study of three New Zealand alpine grasshopper species. N. Z. Joumal of Agricultural Researth, 15:867-877. 